\title{
Assessing the illegal bear trade in Myanmar through conversations with poachers: topology, perceptions, and trade links to China
}

\begin{abstract}
Myanmar is home to Asiatic black bears and sun bears. We gained insight into their hunting and trade in and out of Myanmar through conversations with 40 self-declared bear poachers. All respondents were male who killed or caught typically one to three bears a year, mostly by setting snares. There was a preference for Asiatic black bear. The perception was that bears were less abundant now than five years ago, but it was not more arduous to obtain one. Most poachers $(75 \%)$ would consume the less valuable parts and sell the remainder, whereas others trapped only to sell. Preferred tradable parts were gall bladder, meat, and paws. Chinese were mentioned as playing key roles (ordering, buying, selling) in the trade. Instead of focusing on poachers that infrequently trap bears, we recommend that the authorities should focus on disrupting the trade networks and markets. Better cooperation with neighboring countries, especially China, is needed to stem to flow of bear parts from Myanmar.
\end{abstract}

Keywords: Burma, CITES, Helarctos malayanus, Ursus thibetanus, wildlife trade.

\section{Acknowledgements}

We thank the bear hunters for their collaboration and support and two anonymous reviewers for constructive comments and suggestions for improvement

\section{Introduction}

International wildlife trade remains a leading threat to biodiversity conservation and is a common vector for infectious diseases and invasive species that affect agriculture, livestock, and public health (Phelps, Webb, Bickford, Nijman, \& Sodhi. 2010; Smith et al., 
2009). Although the international wildlife trade involves hundreds if not thousands of species (e.g., Nijman, 2010; Smith et al., 2009), to the general public and many policy makers some species are more commonly associated with this type of trade than other species. In recent years, the trade in live Asian bears, their body parts, and especially their bile has garnered considerable interest due to the impact this has on remaining wild populations and the welfare of the individual bears involved (Dutton, Hepburn, \& Macdonald, 2011; Feng et al. 2009; Foley, Stengel, \& Shepherd, 2011; Kikuchi, 2012; Livingstone \& Shepherd, 2016; Nijman \& Shepherd, 2008). In this article we examine the trade in bears, broadly speaking, from the Republic of the Union of Myanmar (formerly known as Burma), a country that has significant wild populations of two globally threatened bears, and that is economically and geo-politically connected to China and other East Asian consumer countries.

Myanmar is the largest country in mainland Southeast Asia and because of its size and the presence of large wilderness areas, it is of global importance for wildlife conservation (Leimgruber et al., 2005). Two species of bears occur in the country: the sun bear Helarctos malayanus (locally known as khwe won or pashue wet won) and the Asiatic black bear Ursus thibetanus (locally known as wet won). Both are listed as Vulnerable according to the IUCN Red List criteria (Fredriksson, Steinmetz, Wong, \& Garshelis, 2008; Garshelis \& Steinmetz 2008), and now have a fragmented distribution throughout Myanmar, with many local populations no longer being extant. Partially because of the unstable political situation and restrictions imposed by previous authoritarian regimes, little biological fieldwork has been conducted in Myanmar. As such the status of these species within Myanmar remains largely unknown, but there is still the potential that significant populations remain and indeed Myanmar could be one of the more important countries for bear conservation.

Law enforcement with respect to wildlife conservation in Myanmar is weak, and overall Myanmar has a poor record of transparency and accountability (e.g., Gilbert 2014). 
Indeed, Myanmar consistently ranks among the most corrupt countries in the world and ranked 147th out of 167 countries on the Corruption Perception Index, after Cambodia (150th) the worst performer of all the Southeast Asian countries (Transparency International, 2015). Despite these deficiencies, Myanmar has legislation in place to safeguard bears and it has joined international treaties and conventions that, potentially, should benefit bear conservation. In Myanmar the Asiatic black bear is a 'Protected Species' and the sun bear is a 'Totally Protected Species' (Protection of Wildlife and Protected Areas Law, State Law and Order Restoration Council Law No.583/94.1994). Killing or trading bears, their parts, or their derivatives, is not permitted; violation of Law No.583/94.1994 may lead to imprisonment for up to three years and fines of MMK 10,000 ( USD 10 at December 2014 exchange rates) for the Asiatic black bear, or seven years and fines of MMK 50,000 ( USD 50) for the sun bear. Enforcement of wildlife protection laws with respect to bears appears to have been minimal in the last two decades, and indeed despite having worked in Myanmar over this period, we are aware of only very few cases where bear trappers or bear traders have indeed been successfully prosecuted. Burgess, Stoner, and Foley (2014) analyzed seizure data from across Asia for the period 2000-2011 and of the 694 seizures, only 2 were made in Myanmar, ranking the country at the just above Mongolia with one seizure and North Korea with no seizures.

In China, Asiatic black bears are listed as Class II Protected Wildlife Species under the Wildlife Protection Law, whereas the sun bear is listed as a Class I Protected Wild Species. Trading bears or their parts is considered a criminal offence in China and penalties depend on the seriousness of the offence and the value of the parts. For instance, on offender smuggling bear parts valued at between RMB 100,000 and 200,000 (USD 16,250-32,500) shall be liable to fixed-term imprisonment of not less than five years and concurrently to a fine (Zang, 2009). Different from its neighboring countries, the trade in bear bile from Asiatic 
black bear is legal in China, provided it originates from bears kept in bear farms that originate from captive stock. Only bear bile with specific government approval can be sold commercially with the approval denoted by a special label indicating that the bile is from a legal source under government management (Foley et al., 2011).

In 1997, Myanmar joined the Convention on International Trade in Endangered Species of Wild Fauna and Flora (CITES), and the country is an active member of the Association of Southeast Asian Nations - Wildlife Enforcement Network (ASEAN-WEN). Asiatic black bear and sun bear are both listed in Appendix I of CITES, which prohibits international commercial trade of live animals and their parts and derivatives. At various CITES meetings, resolutions have been adopted to mitigate effects of the trade on wild bear populations (Foley et al., 2011). Thus, Resolution Conference 10.8 on the 'Conservation of and trade in bears' was passed in 1997 urging CITES Parties to "take immediate action in order to demonstrably reduce the illegal trade in bear parts and derivatives." Three years later, Parties were urged to implement Resolution 10.8 and to ensure national legislation was in place to control the trade in bear parts or derivatives and to take action with respect to enforcement efforts and penalties for violating laws pertaining to the trade in bear parts. In 2007, Resolution 10.8 was revised urging Parties to increase CITES enforcement and establish or improve national legislation to control the import and export of bear parts and derivatives.

Despite these measures, illegal trade in bears and their parts in Myanmar continues, with frequent reports from wildlife markets including those situated on the borders with Thailand and China (Davies, 2005; Martin, 1997; Shepherd \& Nijman, 2008), and little enforcement efforts have been invested in curbing bear trade (Foley et al., 2011). Myanmar has been assessed by the CITES National Legislation Project as falling in the lowest category 
(i.e., its legislation does not meet the requirements for the implementation and enforcement of CITES).

In 2002-2003 and 2005-2007, Rao and colleagues (2005, 2010, 2011) interviewed and collected data from hunters returning from hunts and compiled trade data collated at patrol checkpoints in and around Hkakaborazi National Park in northern Myanmar (Kachin State). Bears were cited as top priority for $49 \%$ of hunters interviewed (i.e., they were perceived as the most valuable or most profitable), but were only obtained in about $2 \%$ of hunting trips. Based on the trade data collated, about $14 \%$ of the trade referred to bear parts (making bears the fourth common taxon in trade) and almost all trade was destined for China.

More contemporary information on the threats facing bears, and in particular the threats posed by hunting and trade in Myanmar are not readily available. Furthermore, what drives the trade and what motivates people to kill bears remains obscure. In 2013 and 2014, as part of a larger study into the trade in bears in Myanmar, we had the chance to discuss these topics with 40 respondents that were self-declared poachers of bears. Here, we address the following five interlinked research questions:(a who is it that poach bears in Myanmar; (b) which of the two species of bears are hunted and are there any geographic differences; (c) what hunting methods are used and which are used most frequently; (d) what is the perceived abundance of bears; and (e) what is the reason, or reasons, for hunting bears and, what is their economic value to poachers? We report our findings here to improve the understanding of how bears are targeted and what drives the trade.

\section{Methods}

The survey was initiated by TRAFFIC and conducted by a team led by the last author between 18 May 2013 and 4 September 2014 in nine States or Districts (Figure 1). Upon arrival in villages, the team would initially target bus drivers or trishaw or motorbike taxi drivers to guide us to bear traders and bear poachers (given the protective status of bears in 
Myanmar and the illegality of their trade we refer to those killing bears as poachers but we note that, to the best of our knowledge, none of the poachers we spoke to has been convicted of poaching, and poachers may go out to hunt non-protected species alongside bears). Traditional Asian Medicine shops were visited and enquiries were made to locate bear poachers. All 40 respondents were male, with an average age of 40 years (range $21-81$ years). They came from 23 different villages or towns in 9 States or Regions, i.e. 10 from Thanintharyi, 7 from Rakhine, 5 from Chin, 5 from Magway, 4 from Sagaing, 4 from Shan, 3 from Bago, 1 from Mon and 1 from Kachin. One of the aims of this study was to get an even spread of respondents from different parts of the country, and although that was largely achieved, there still was a slight bias toward the south and southwestern part of the country. Due to difficulties of working in certain States — especially Shan and Kachin-relatively few bear poachers were met in villages or States that border or that are situated close to China.

\section{Insert Figure 1 here}

All conversations were held in Burmese and were conducted in the respondent's house, a communal meeting area, or, occasionally in the field. A field guide (Parr \& U Thin Than, 2009) was used to guide the discussion. The conversations took the form of a thematic, topic-centered, narrative approach where all aspects of bear hunting, killing, and trade were covered, but that still had a fluid and flexible structure to allow us to deviate if that was thought to be relevant. The conversation was an interaction between respondent and the surveyor, leading to the construction or reconstruction of knowledge. All information was transcribed in Burmese into notebooks at the time of the discussion. At the end of the discussion, we repeated key points to ascertain whether we captured the essence of the respondent's opinions / expressions correctly. Respondents did not receive gifts or money for their participation. For analysis, information that was relevant to the present study was 
extracted, translated into English, and transferred to an excel database. Data were coded without a prior coding system and were guided by the data generated by the respondents, thus allowing us to be all-inclusive and flexible. Prior to analysis, the first and last author discussed the accuracy of the entries at length to minimize translation and extraction errors, and to ensure that the intentions of the informants were accurately captured.

Attitudinal data are presented as response frequencies for the entire sample using response categories constructed from the replies. Where multiple responses were given to a question (e.g., killing bears for gall and obtaining cubs as the reason for hunting), data are presented as the percentage of respondents giving each response, and so may sum to over 100 percent.

The exchange rate we used is that of December 2014 (i.e. mid-way in the data collection period) when MMK 1,000 equaled USD 1.004. A common measure to report weight in South Asia is the viss, which is equal to $1.63 \mathrm{~kg}$. Unit of measurements are $100 \mathrm{~g}$ for bile and $1 \mathrm{~kg}$ for meat and other parts. When reporting prices collected by other researchers in Myanmar, these were inflation-corrected so that all prices were comparable; all percentages are rounded up to the nearest whole number.

\section{Results}

\section{Who hunts bears in Myanmar?}

When asked about their occupation, none of the informants identified themselves solely as hunters (of bears or other wildlife) and only seven informants (18\%) saw themselves as hunters and farmers or hunters and gardeners (4 from Chin, 2 from Thanintharyi, 1 from Magway). One informant (3\%) from Thanintharyi was a professional collector of non-timber products (primarily agarwood). Most people had other occupations and poaching bears was not seen as part of their occupation. Twenty-two informants (55\%) 
considered themselves farmers or gardeners, four $(10 \%)$ were merchants or shop-owners, and three $(8 \%)$ were village heads or administrators.

\section{What bears are poached where?}

Informants from the two northernmost States, Sagaing and Kachin, as well as the one from Mon, were of the opinion that only the Asiatic black bear was present in their area, as were at least some informants from Rakhine (two out of five), Bago (one out of three), and Thanintharyi (one out of ten). Only one informant from Thanintharyi indicated that only sun bears were present in the area where he poached bears. The other 29 informants (73\%) lived in areas where they encountered both sun bears and Asiatic black bears. Of these 29 informants that had both species of bear in their area, only four, all from Chin, indicated a preference of one species over the other when going out hunting, with all preferring Asiatic Black Bears.

\section{What poaching methods are used and at what frequency?}

None of the 40 informants indicated that they ever specifically hunted for bears instead bears were poached alongside other species or were caught opportunistically. The preferred method of poaching bears was by means of setting snares, mostly made out of nylon or steel wire (rope or vine snares are used for ground-dwelling birds and smaller wildlife). Snares were used by 30 informants (75\%), 11 of whom indicated they additionally used guns and four who used snares as well as spears and dogs. Nine poachers $(23 \%)$ relied solely on guns and one hunted with guns and dogs.

Most respondents were not able to indicate the number of bears they had poached or the frequency at which they caught bears, merely indicating they obtained them “occasionally" or "sometimes". Four hunters stated they, on average, caught one bear every two years, ten caught on average one bear a year, and two stated that, on average, they caught two to three bears a year. These 16 respondents thus kill on average just over one bear each a 
year (Figure 2); some of the respondents that gave merely an indication of the numbers of bear they poach may not have been able to provide a more quantitative estimate because of the infrequent nature of the kills or because of their reluctance to convey this information to outside parties.

\section{Insert Figure 2 here}

\section{Perceived abundance of bears}

Thirty respondents $(75 \%)$ indicated there were fewer bears now in the area where they were living compared to five years ago. Six respondents $(15 \%)$ were of the opinion that this decline was due to deforestation, and another $11(28 \%)$ indicated they thought the primary reason for the decline in bear numbers was an increase in hunting pressure or an increase in poachers. None of the respondents was of the opinion that there were now more bears than five years ago, and of the 10 who indicated that numbers had remained stable, five were from Myanmar's southernmost State of Tanintharyi. None of the 40 respondents thought it was more difficult for them to catch or trap bears, and although one respondent (from Bago) indicated he now had to travel a longer distance to encounter bears, $38(95 \%)$ indicated that this was not the case.

\section{Reasons for poaching bears and economic value}

When asked what they did when they caught a bear, two poachers indicated they would use it for their own consumption, 31 (78\%) would consume some of the parts and would sell other parts, especially the more valuable ones (e.g., gall, bear paws). The average price for gall bladder was USD 298.04+/-444.46 per 100 gram ( $\mathrm{n}=16$ independent quotes) and that of bear meat was USD $5.19+/-4.90$ per $\mathrm{kg}(\mathrm{n}=4$ independent quotes).

Six poachers (15\%) trapped bears to sell. This included the two poachers from Rakhine who reported catching two to three bears a year and sold these immediately, neither using any of part of the bears for themselves. Just under half of the bear poachers indicated 
they had been asked by Chinese national living in Myanmar or a Burmese citizen of Chinese descent to poach or supply bears, with the knowledge that they then would buy the bears from them. Six poachers would sell their wares to local brokers or middlemen. Six of the 10 poachers in Thanintharyi indicated that no outsiders were involved in the trade.

The leading reason for poaching bears, mentioned by 38 of the 40 informants, is to obtain (and sell) the gall bladder. Thirtyfour hunters indicated more than one reason for poaching bears. Five listed gall bile as their only reason for poaching bears and a further 15 mentioned it as first on the list of reasons why bears were poached. Eight of the 12 poachers who indicated that finding cubs was a reason for their hunting trips listed this as their first (and possibly prime) reason for doing so (Figure 3). None of the informants indicated humanbear conflict or crop-raiding as a reason to poach bears.

\section{Insert Figure 3 here}

There appear to be only small geographic differences in the reason for poaching bears: to obtain gall bladders was mentioned in all parts of the country, and obtaining bear meat and / or bear paws were other incentives that are present throughout most of the country (Table 1).

\section{Insert Table 1 here}

\section{Discussion}

Here we showed through discussions with poachers, that bears are a preferred species for these poachers even though they do not specifically set out to target bears. The most common method of hunting - by setting snares - is non-specific (cf. Rao et al. 2005), and besides bears other species including red muntjak Muntiacus muntjak, takin Budorcis taxicolor, Chinese serow Capricornis milneedwardsi, and Chinese goral Naemorhedus griseus are caught (Nijman, 2015). While snares were used by $75 \%$ of the bear poachers, half used guns, either on their own or in combination with dogs or snares. Rao et al. (2005) 
reported that $72 \%$ of hunting wildlife was done using nylon or steel snares and, decidedly different from our study, less than 1\% used guns. Similarly, Rabinowitz and Saw Tun Khiang (1998) found that hunters in northern Myanmar used snares, dogs and crossbows, but rarely guns. The higher prevalence of guns used in our study is probably because all of our respondents were bear poachers who, in addition hunted other wildlife, whereas Rao et al. (2005, 2010, 2011) and Rabinowitz and Saw Tun Khiang (1998) indiscriminately included all hunters in their studies. .

The prime reason for poaching bears is to obtain the gall bladder so it can be sold to traders. Although bear meat is often consumed when a bear is killed, more commercial valuable parts, including the gall bladder, paws, and skins, are to supply the demand from traders. Likewise, bear cubs are a valuable commodity and are intended for the commercial trade. If the views of these poachers are representative of the hunting community in Myanmar as a whole, then it is clear that the main driver for the bear trade was demand from outsiders, including Chinese nationals. If the demand from China for gall bladders, paws, and cubs, were to greatly diminish still nearly half of poachers in Myanmar would be interested in obtaining bear meat. Given that a proportion of the bears were claimed to have been taken incidentally, demand reduction from China in itself would not bring a total stop to the illegal poaching of bears in Myanmar. As indicated earlier, bear poachers at present do not expect a realistic chance of punishment, and even if they are caught (and there are no indications to suggest that this is a frequent occurrence as seizure data suggest this happened only twice over a 12 year period: Burgess et al., 2014) then the fines that can be imposed after successful prosecution are minimal relative to the value of the meat and gall bladder.

Nijman (2015) reviewed the poaching and trade in Asiatic black bears and, to a lesser extent, sun bears in the Imawbum Mountains, in the eastern part of Kachin State and bordering Yunnan, based on field surveys conducted in the period 2010-2014. Bears were 
clearly the main target species for trapping in the Imawbum Mountains. Information obtained from hunters suggested that prior to the year 2000, bears were primarily poached with guns and occasionally by setting snares. Chinese logging companies started operating in the area in 2001 increasing both the demand for wildlife products and increasing the availability of Chinese iron traps. This led to a drastic increase in the hunting pressure on bears. Indeed, a number of Lisu hunters are now specialized in bear poaching, and their livelihood is hunting and trapping for the Chinese wildlife market. In recent years, meat-baited iron traps has become the main hunting method for bears in the Imawbum Mountains. Specialized bear poachers typically set about 50 to 100 iron traps, checking them every 5 to 7 days. Skulls of Asiatic black bear and sun bear are displayed on trophy boards in village houses (in a ratio of at least 5:1). Other bear parts such as gall bladders, meat, rendered fat, claws and paws are sold to Chinese traders, with the border town of Kangfang acting as the main gateway into China. Hunters in Nijman's (2015) study agreed that the population of both Asiatic black bear and sun bear had declined in recent years due to the high hunting pressure. This picture from Kachin is different from what we encountered in the present study (where only one informant was from Kachin) in that we did not find any specialized bear poachers nor did any of the poachers employ iron traps, but it is similar in that the main drivers of the trade is the demand in China and in both studies respondents agreed that the populations of bears appeared to be declining.

Qualitatively, we found few differences between the nine States or Districts, even for those with few respondents included in this study. The exception appeared to be Thanintharyi in the south of Myanmar, close to the border with Thailand. Here, sun bears and Asiatic black bears are present, it is the area where proportionally most hunters indicated stable populations, and the influence of outsiders on the trade appears to be less than in other parts of Myanmar. 
Intriguingly, not a single one of the 40 respondents thought it was more difficult for them to catch or trap bears. Likewise, only one respondent (from Bago) indicated that he now had to travel a longer distance to encounter bears, but 38 respondent indicated that this was not the case. At first difficult to reconcile this -respondents see fewer bears, but they have to travel the same distance and they catch as many as before. However, once one considers that all poaching is done opportunistically with each hunter catching on average one bear a year, if that, and none of the hunters expecting to catch bears to begin with, then it becomes clear that these assertions are not conflicting.

Rao et al. (2010) reported on the economic value of bear parts in Kachin State in 2005-2007 as assessed by hunters and obtained inflation-corrected prices of USD $0.54+/-0.05$ for a $\mathrm{kg}$ of bear meat, and USD 194.17+/-97.85 per $100 \mathrm{~g}$ of gall bladder. If these prices were representative for the trade in Myanmar at the time, then the price for bear meat has increased more than ten-fold, and that of gall bladder has doubled. Foley et al. (2011) reported on 2010 prices of gall bladders in the border towns of Mong La (USD 51.82 when corrected for inflation) and Tachilek (USD 59.16, inflation corrected), but given that no weight was reported, these data are not comparable to ours or to those of Rao et al. (2010).

Based on the information obtained from the bear poachers it is clear that bear poaching in Myanmar continues and that at least in part this is driven by demand from across the border. To reduce illegal international trade of bears, their parts or derivatives, Myanmar should be encouraged to work closely with other countries, especially China, and other relevant countries, as international co-operation is essential to enforce CITES effectively and to put an end to the illegal international trade in bear parts (Shepherd \& Nijman, 2008). The domestic trade in bears and their parts in Myanmar require more focused efforts from the Myanmar authorities. This almost certainly requires an increase in law enforcement and effective prosecution as this currently is amongst the least effective in Asia (Foley et al., 
2011) and possibly a change in penalties for law breakers (as this appears to be imbalanced, with prosecutors only being able to demand very low monetary fines but relatively long prison sentences).

\section{References}

Burgess, E. A., Stoner, S. S., \& Foley, K. E. (2014). Brought to bear: An analysis of seizures across Asia (2000-2011). Petaling Jaya, Malaysia: TRAFFIC South East Asia.

Davies, B. (2005). Black market: Inside the endangered species trade in Asia. San Rafael, CA: Earth Aware Editions.

Dutton, A. J., Hepburn, C., \& Macdonald, D. W. (2011). A stated preference investigation into the Chinese demand for farmed vs. wild bear bile. PloS One, 6(7), e21243.

Feng, Y., Siu, K., Wang, N., Ng, K. M., Tsao, S. W., Nagamatsu, T., \& Tong, Y. (2009). Bear bile: Dilemma of traditional medicinal use and animal protection. Journal of Ethnobiology and Ethnomedicine, 5(1), article 2.

Foley, K. E., Stengel, C. J. \& Shepherd, C. R. (2011). Pills, powders, vials and flakes: The bear bile trade in Asia. Petaling Jaya, Malaysia: TRAFFIC South East Asia.

Fredriksson, G., Steinmetz, R., Wong S., \& Garshelis, D. L. (2008). Helarctos malayanus. The IUCN Red List of Threatened Species 2008: e.T9760A13014055. Downloaded on 27 February 2016.

Garshelis, D. L., \& Steinmetz, R. (2008). Ursus thibetanus. The IUCN Red List of Threatened Species 2008: e.T22824A9391633. Downloaded on 27 February 2016.

Gilbert, O. T. (2014). Global analytical lessons for evaluating a Myanmar sovereign wealth fund. Pacific Rim Law \& Policy Journal, 23, 579-632.

Kikuchi, R. (2012). Captive bears in human-animal welfare conflict: A case study of bile extraction on Asia's bear farms. Journal of Agricultural and Environmental Ethics, $25,55-77$. 
Leimgruber, P., Kelly, D. S., Steininger, M. K., Brunner, J., Müller, T., \& Songer, M. (2005). Forest cover change patterns in Myanmar (Burma) 1990-2000. Environmental Conservation, 32, 356-364.

Livingstone, E., \& Shepherd, C.R. (2016). Bear farms in Lao PDR expand illegally and fail to conserve wild bears. Oryx, 50, 176-184.

Martin, E.B. (1997). Wildlife products for sale in Myanmar. TRAFFIC Bulletin, 17, 33-44.

Nijman, V. (2010). An overview of international wildlife trade from Southeast Asia. Biodiversity and Conservation, 19, 1101-1114.

Nijman, V. (2015). The conservation status of mammals and birds in the Imawbum Mountains, Kachin State, Northern Myanmar. Cambridge, UK: Fauna and Flora International.

Parr J. W. K., \& U Thin Than (2009). Large mammals of Myanmar. Washington DC: World Bank.

Phelps, J., Webb, E. L., Bickford, D., Nijman, V., \& Sodhi, N. S. (2010). Boosting CITES. Science, 330, 1752-1753.

Rabinowitz, A., \& Saw Tun Khaing (1998). Status of selected mammal species in North Myanmar. Oryx, 32, 201-208.

Rao, M., Tan Myint, Tan Zaw, \& Saw Htun. 2005. Hunting patterns in tropical forests adjoining the Hkakaborazi National Park, north Myanmar. Oryx, 39, 292-300.

Rao, M., Saw Htun, Tan Zaw, \& Tan Myint (2010). Hunting, livelihoods and declining wildlife in the Hponkanrazi Wildlife Sanctuary, North Myanmar. Environmental Management, 46, 143-153.

Rao, M., Tan Zaw, Saw Htun, \& Tan Myint (2011). Hunting for a living: Wildlife trade, rural livelihoods and declining wildlife in the Hkakaborazi National Park, North Myanmar. Environmental Management, 48, 158-167. 
Shepherd, C. R., \& Nijman, V. (2007). An assessment of wildlife trade at Mong La market on the Myanmar-China border. TRAFFIC Bulletin, 21, 85-88

Shepherd, C. R., \& Nijman, V. (2008). The trade in bear parts from Myanmar: An illustration of the ineffectiveness of enforcement of international wildlife trade regulations. Biodiversity and Conservation, 17, 35-42.

Smith, K. F., Behrens, M., Schloegel, L. M., Marano, N., Burgiel, S., \& Daszak, P. (2009). Reducing the risks of the wildlife trade. Science, 324, 594-595.

Zang, Y. 2009. Conservation and trade control of pangolins in China. Pp 66-74 in S. Pantel, \& S. Y. Chin (Eds.), Proceedings of a workshop on trade and conservation of pangolins native to South and Southeast Asia. Petaling Jaya, Malaysia: TRAFFIC South East Asia. 
Figure 1. Myanmar listing the States where the bear hunter survey was conducted; black squares are centers of trade in bear parts and arrows show the flow of trade in bears as indicated by respondents and information from traders (from Foley et al., 2011; Nijman, 2015; Shepherd \& Nijman, 2008; this study).

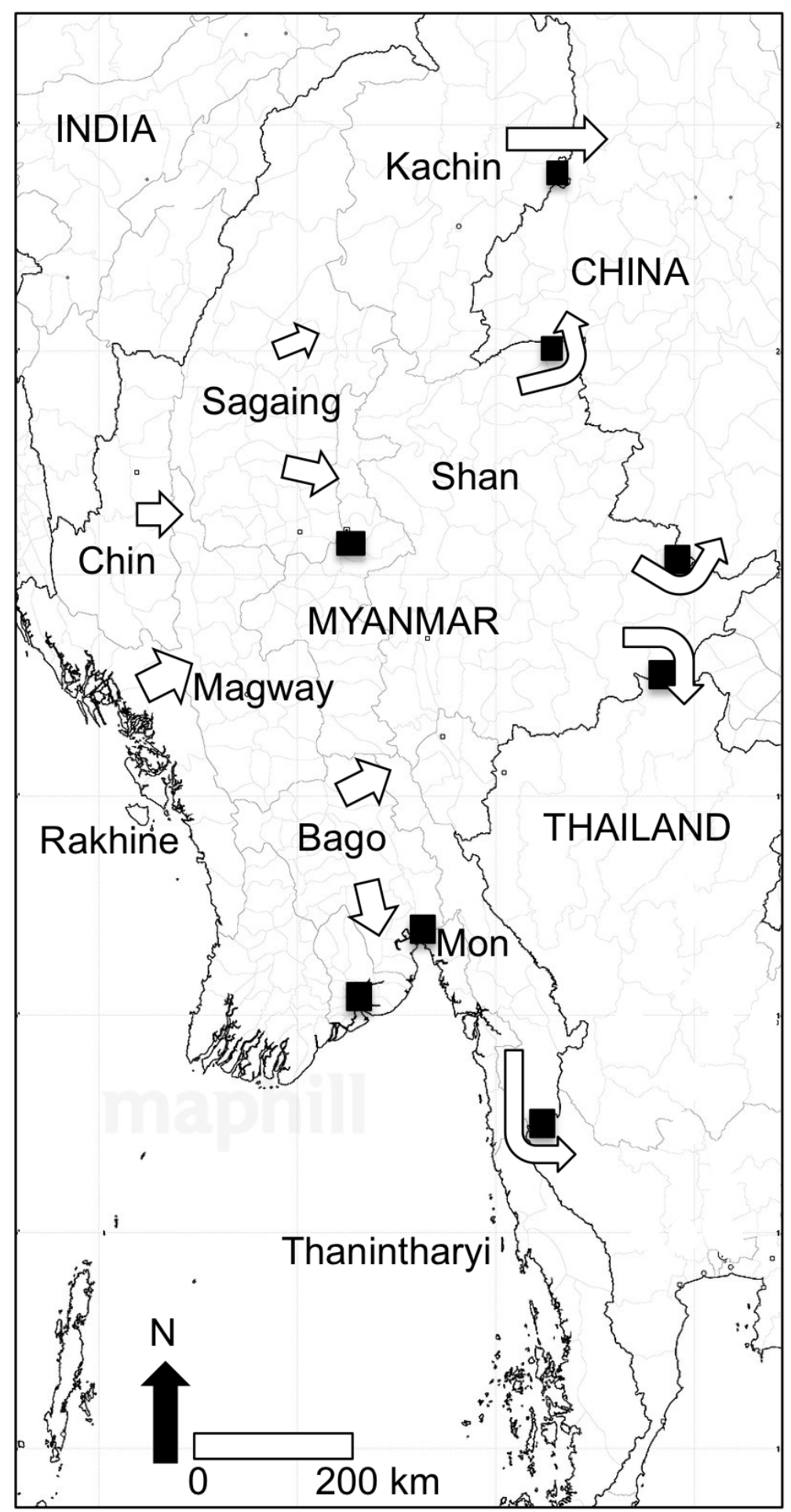


Figure 2. Frequency of killing bears as reported by hunters in Myanmar - the line indicates the cumulative number of bears hunted annually.

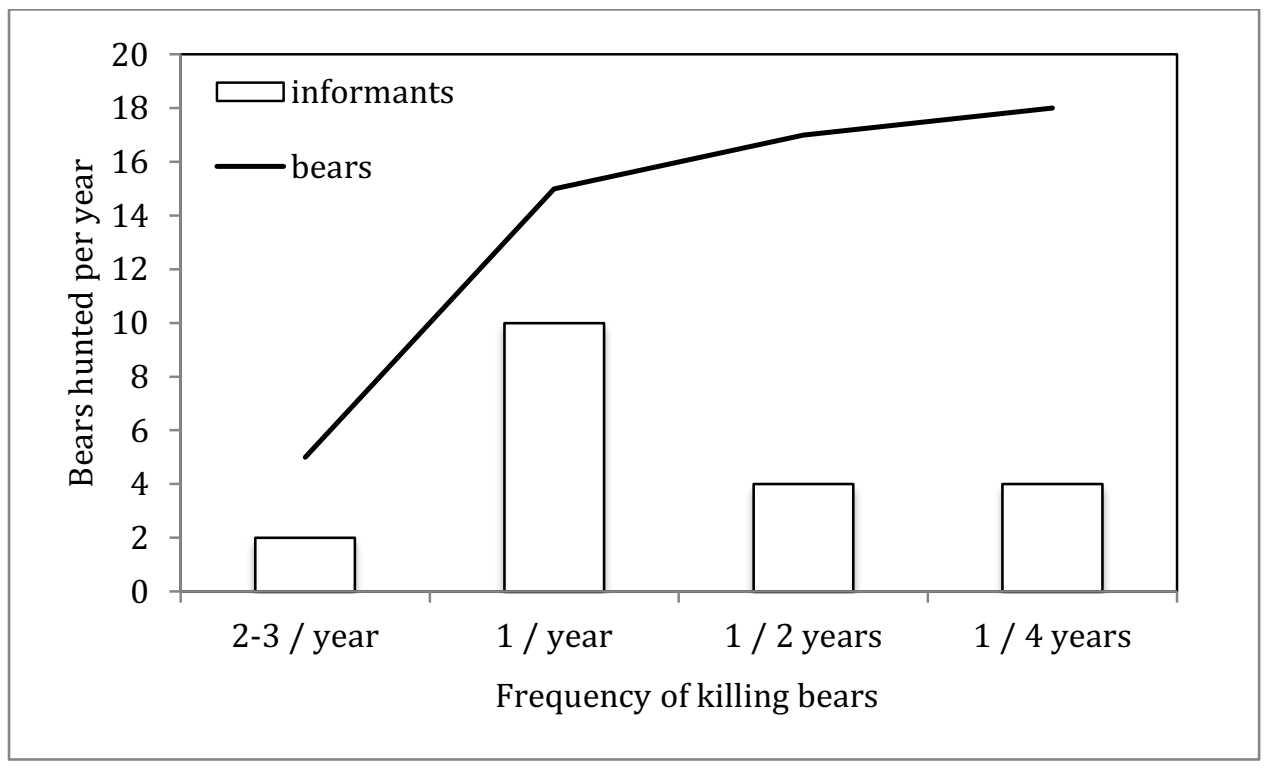


Figure 3. Motivations for hunting Asiatic black bear or sun bear in Myanmar according to 40 self-declared bear hunters; white bars are based on all answers, i.e. all motivations, black bars are the primary motivations (i.e. the motivations that were given first and that are probably perceived to be more important).

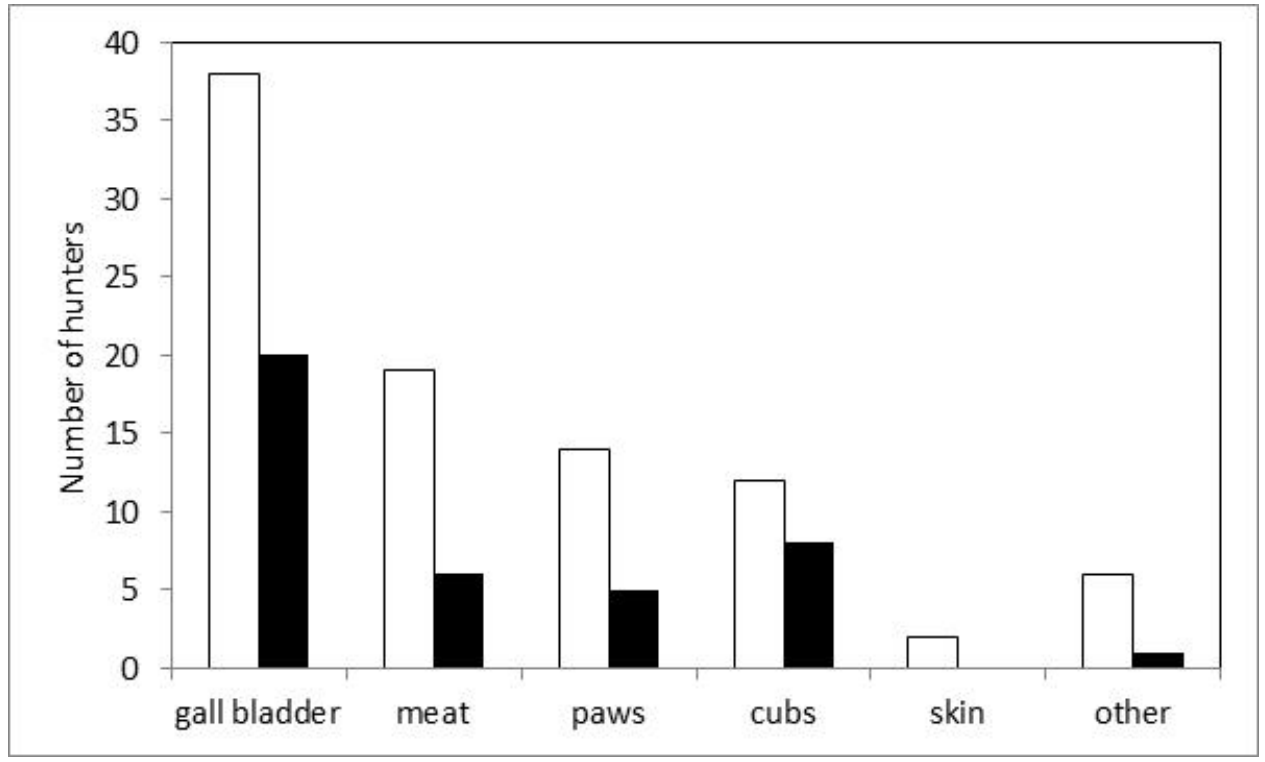


Table 1. Geographic variation in motivations for hunting bears in Myanmar based on information from 40 informants.

\begin{tabular}{|c|c|c|c|c|c|c|}
\hline State (informants) & Gall bladder & Meat & Paws & Cubs & Skin & Other \\
\hline Thanintharyi (10) & $\mathrm{x}$ & $\mathrm{x}$ & $\mathrm{x}$ & $\mathrm{x}$ & & $\mathrm{x}$ \\
\hline Rakhin (5) & $\mathrm{x}$ & $\mathrm{x}$ & & & $\mathrm{x}$ & $\mathrm{x}$ \\
\hline Magway (5) & $\mathrm{x}$ & $\mathrm{x}$ & & & & $\mathrm{x}$ \\
\hline Chin (5) & $\mathrm{x}$ & & $\mathrm{x}$ & & & $\mathrm{x}$ \\
\hline Sagaing (4) & $\mathrm{x}$ & & $\mathrm{x}$ & $\mathrm{x}$ & $\mathrm{x}$ & \\
\hline Shan (1) & $\mathrm{x}$ & $\mathrm{x}$ & $\mathrm{x}$ & $\mathrm{x}$ & & \\
\hline Kachin (1) & $\mathrm{x}$ & & $\mathrm{x}$ & $\mathrm{x}$ & $\mathrm{x}$ & \\
\hline Mon (1) & $\mathrm{x}$ & $\mathrm{x}$ & & $\mathrm{x}$ & & \\
\hline Bago (1) & $\mathrm{x}$ & $\mathrm{x}$ & & & & \\
\hline
\end{tabular}

